\title{
Bioética y asistencia de la salud
}

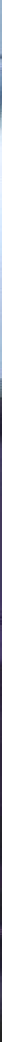

A aplicação da deliberação moral na pesquisa empírica em bioética

The use of moral deliberation in empirical research in bioethics

(1) Autor

\section{Elma Zoboli}

Escola de Enfermagem da Universidade de São Paulo

E-mail: elma@usp.br 
Resumo

Abstract
0 artigo apresenta pesquisa empirica integrada em ética que aplicou a deliberação moral, na concepção teórico-filosófica e proposta metódica de Diego Gracia, como referencial teórico-metodológico. A aplicação mostrou-se capaz de dar conta da dinâmica do objeto estudado na vida real, pois possibilitou que a partir da situação apresentada os participantes incluíssem o que consideravam para lidar com o conflito de valores das vinhetas usadas na coleta de dados. Propiciou, também, a integração das abordagens filosófica e empirica na pesquisa em bioética. A categoria analítica da prudência permitiu avaliar os resultados de maneira crítica e compreensiva.

The article presents an integrated empirical ethics research project that used the moral deliberation, according to the theoretical and philosophical conception, and methodical proposal of Diego Gracia, as a theoretical and methodological framework. The application showed the potential to realize the dynamics of the studied object in real life, making it possible, from the situation presented in the vignettes, for participants to include what they considered for dealing with the conflict of values. Italso made the integration of philosophical and empirical approaches in bioethics research possible. The analytical category of prudence allowed the results to be assessed in a critical and comprehensive way.

Atenção primária à saúde, bioética clínica, deliberação moral, análise ética, pesquisa em bioética.

Primary health care, clinical bioethics, moral deliberation, ethical analysis, empirical ethics.

Recibido: 21/5/2016. Aceptado: 14/6/2016. 


\section{Introdução}

Este artigo traz resultados que sintetizam três pesquisas empíricas em bioética desenvolvidas no município de São Paulo (Brasil) numa empreitada acadêmica voltada para compreender a deliberação moral na Atenção Primária à Saúde (APS). Os estudos se ancoraram na bioética deliberativa, sendo a deliberação inicialmente tomada como norte teórico e, por fim, como referencial teórico-metodológico para uma pesquisa empírica integrada em ética, cujos resultados são parcialmente apresentados neste artigo. 0 uso do procedimento deliberativo, proposto por Diego Gracia para a bioética clínica (Gracia, 1992; Gracia, 2009), na

Os problemas éticos na Atenção Primária à Saúde envolvem

as relações dos profissionais

com os usuários, equipe, a

organização do serviço e

sistema de saúde, atingindo

seis dimensões. análise de dados empíricos de pesquisas em ética pode ser visto como um exemplo da fertilidade da bioética ibero americana, pois a proposta é fruto do estágio de pós-doutorado da autora, que atua no Brasil, com o Professor, na Universidad Complutense de Madrid em 2009. Assim, por considerar o uso da deliberação para a pesquisa em bioética como um fruto da profícua interação ibero-americana na área escolhi apresentar parte dos resultados ${ }^{1}$ do estudo que propôs este inovador desenho de pesquisa como contribuição para este novo periódico que, por certo, consolidará ainda mais esta frutuosa relação.

\section{Questões éticas na APS e deliberação moral}

Problemas éticos são situações vividas pelos profissionais da APS como fontes de conflitos de valores e deveres para as quais vislumbram vários cursos de ação, mas nenhum parece totalmente satisfatório, pois um valor obscurece o outro, um dever encobre o outro e o profissional fica sem saber como agir, sente-se em meio a um eclipse do sentimento de obrigatoriedade, ficando perplexo (La Taille , 2006). Nestas situações, é preciso deliberação e ponderação para chegar ao melhor caminho, a alternativa ótima para resolução do conflito, ou seja, a via que permitirá comtemplar a concretização de todos os valores em conflito, conciliando-os (Gracia, 2009). Assim, é preciso abrir o leque de possibilidades de solução, de cursos de ação para a resolução do problema, para que as escolhas não sejam dilemáticas, do tipo 'ou um ou outro', mas conciliatórias.

Os problemas éticos na APS envolvem as relações dos profissionais com os usuários, equipe, a organização do serviço e sistema de saúde, atingindo seis dimensões: Gestão da APS; Longitudinalidade; Prática das equipes; Perfil profissional; Privacidade na APS, e Sigilo profissional. Na relação entre profissionais e usuários, os problemas éticos são: informação ao usuário; privacidade e confidencialidade; sigilo; falta de respeito com o usuário; recusa dos usuários às orientações profissionais; usuários não aceitam

1 O estudo completo está em (Zoboli, 2010), tese de livre docência: Deliberação: leque de possibilidades para compreender os conflitos de valores na prática clínica da atenção básica. 
o serviço oferecido, ainda que os profissionais considerem-no o mais indicado para o caso. Na relação entre os profissionais da equipe, aparecem: demanda excessiva para atendimento nos serviços; pouco diálogo e compreensão; falta de cooperação, compromisso e confiança; desrespeito; despreparo dos profissionais para a APS; desgaste psíquico pelo trabalho. Quanto ao sistema de saúde, os

Para solucioná-los não há receitas prontas, ao contrário, os problemas éticos precisam de avaliação constante e contínua para abrir o leque das possíveis saídas. problemas são: recursos humanos insuficientes para a demanda de atendimento; alta rotatividade dos profissionais; escassos recursos financeiros; carência na estrutura física; dificuldades no sistema de referência e contra referência; falta de apoio institucional. (Dalla Nora, Zoboli, \& Vieira, 2015). Os problemas éticos da APS emergem aos profissionais tentarem responder às necessidades de saúde da população, considerando os contextos socioculturais e econômicos dos envolvidos, que atravessam a situação conflituosa e a compreensão desta (Zoboli \& Fortes, 2004; Junges, 2014). Para solucioná-los não há receitas prontas, ao contrário, os problemas éticos precisam de avaliação constante e contínua para abrir o leque das possíveis saídas, com vistas a respostas de longo alcance, deliberadas e prudenciais (Dalla Nora, Zoboli, \& Vieira, 2015).

A deliberação moral é a consideração dos valores e deveres implicados em um fato concreto, a fim de conduzir a situação conflituosa por um caminho razoável, prudente e realizável. Razoável refere-se ao conhecimento prático que maneja, com moderação e justa medida, as possibilidades e probabilidades diante da incomensurabilidade da realidade de casos concretos. Não sendo uma vertente idealista, pragmática ou utilitarista, a deliberação não visa chegar à decisão ideal, certa, maximizadora de resultados, não tem pretensão de universalidade e certeza, sem que isto signifique incorrer em relativismos. Nas situações de incerteza, como os conflitos morais, quando não se sabe o que fazer, as decisões precisam ser prudentes, incluindo distintas aproximações e perspectivas do caso para enriquecer o diálogo e a compreensão do conflito. Ao deliberar interpretam-se dados, fatos e as conexões de sentido destes que se dão nos valores, perfazendo uma empreitada hermenêutica, ou seja, a interpretação de eventos no conjunto da vida e como parte desta. A deliberação moral, então, é um meio sistematizado e contextualizado de análise dos eventos da vida, dos acontecimentos históricos e culturais ao cabo do qual é possível explicar, argumentar e justificar as eleições morais feitas. Quem delibera precisa admitir a existência de mais soluções dos que as vislumbradas à primeira vista, com abertura para novos descobrimentos, novas perspectivas interpretativas. Isso é importante para bem deliberar, pois as soluções vistas por primeiro são as extremas, que levam a realização de um dos valores em conflito com detrimento total do outro.

Por aspirar cursos razoáveis e de caráter aberto, o equacionamento deliberativo não é um processo de quantificação, mas de argumentação que apresenta de maneira fundamentada e justificada as razões das escolhas morais. Assim, a deliberação admite uma variabilidade de soluções igualmente prudentes e não somente uma única, a correta, pois as interpretações da situação pelos envolvidos e afetados diferem. Por meio da articulação das várias perspectivas interpretativas, com a inclusão das vozes, 
preocupações e interesses de todos os envolvidos e afetados (Leder , 1994), o que se busca é a solução ótima, que realize ao máximo os valores em conflito ou os lese o menos possível (Gracia, 2009).

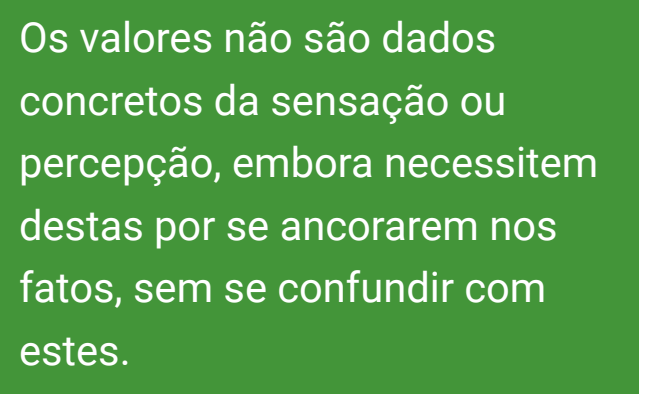

0 encadeamento existente entre fatos, valores e deveres é fundamental na construção dos juízos morais, na deliberação. Na proposta de Diego Gracia, estes três âmbitos da experiência moral originam três momentos distintos do procedimento deliberativo. 0 momento dos fatos orienta-se pela lógica cognitiva; é o momento cognitivo da deliberação. 0 momento da valoração, estimação ou preferências refere-se aos valores e o da realização destes é o momento do dever, do ato voluntário, o mais propriamente moral. A moral envolve, então, as faculdades cognitiva (fatos), emocional (valores) e volitiva (deveres) da inteligência humana. Fato é todo dado de percepção, da realidade, observável por qualquer um, portanto, algo objetivo, contundente, impositivo. A tudo que percebemos, necessariamente, atribuímos um valor. Os valores não são dados concretos da sensação ou percepção, embora necessitem destas por se ancorarem nos fatos, sem se confundir com estes. Não há fatos puros, estes sempre estão acompanhados dos valores, como seus depositários que são, entretanto, os dois não podem ser confundidos na deliberação, pois a ética não trata diretamente dos fatos ainda que parte destes para deliberar. A estimação dos valores não depende só da percepção ou dos sentimentos, pois, ainda que estes sejam qualidades reais das pessoas, coisas e ações, também são frutos de construção individual, social, histórica e cultural. Os fatos carregam os valores e estes sustentam os deveres, que formam o âmbito mais próprio da ética e da Bioética, pois a experiência moral é a experiência do dever. Os valores demandam sua realização, ou seja, requerem se tornar realidade, ganhar corpo, encarnar-se e esse é o dever próprio da ética: realizar valores. (Gracia, 1992; Gracia, 2009; Zoboli, 2010).

Considerando o entrelaçamento de fatos, valores e deveres na experiência moral, os momentos do procedimento deliberativo são: deliberação sobre os fatos (apresentação do caso descoberto como problema ético; esclarecimento dos fatos do caso); deliberação sobre valores (identificação dos problemas morais do caso; indicação do problema moral fundamental; identificação dos valores em conflito); deliberação sobre os deveres (identificação dos cursos de ação extremos; identificação dos cursos de ação intermédios; identificação do curso de ação ótimo) (Gracia 2009; Zoboli, 2012; Zoboli, 2013).

O ponto final deste itinerário é a prudência, assim, os cursos de ação são prudentes ou imprudentes e não verdadeiros ou falsos como nos equacionamentos apodíticos. A decisão prudente é o 'melhor' para um dado momento concreto. Na linguagem atual, a 'prudência' perdeu o sentido ético e significa cautela, precaução; ser prudente, então, passou a significar saber tomar precauções contra um ou vários perigos ameaçadores. Entretanto, na deliberação toma-se a prudência como o conceito radicalmente grego, mais particularmente aristotélico, que é. Para Aristóteles, o pensamento, ou conhecimento, era prático, produtivo ou teórico, situando-se a prudência no primeiro, 
onde estão as questões humanas, ocorre a ação humana, não se devendo tratá-las com os mesmos conceitos e métodos destinados aos objetos imutáveis, alvos da ciência teórica. Assim, a prudência é uma sabedoria prática, enquanto uma maneira de agir, um tipo de saber que se articula com o teórico na experiência da vida vivida, pois as ações humanas requerem uma disposição racional verdadeira e prática, para a ação, quanto ao que é melhor para o ser humano. A disposição prática da prudência implica uma regra da escolha não restrita à retidão da ação, mas que inclui a correção do critério, entendendo que a ética torna os seres humanos virtuosos e felizes pela prática habilidosa das virtudes. Aristóteles retratava o homem prudente como o que sabe avaliar os obstáculos, tirar partido das características singulares de uma dada situação, escolher o momento oportuno para todo empreendimento, a fim de atingir

A disposição prática da

prudência implica uma regra da

escolha não restrita à retidão da

ação, mas que inclui a correção

do critério, entendendo que a

ética torna os seres humanos

virtuosos e felizes pela prática

habilidosa das virtudes. o objetivo final da felicidade humana. Ou seja, é prudente quem atua prevendo, ao máximo possível, o inesperado. 0 prudente tem como prática fundamental a deliberação, que propicia o melhor para si próprio, mas não unicamente, porque a vida feliz transcende os fins particulares; é uma totalidade concreta que inclui o bem da comunidade e do indivíduo. Assim, o prudente não é um puro empírico que vive o dia-a-dia sem princípios e sem perspectivas, mas é o que tem visão de conjunto. (Pellegrin, 2007; Aubenque, 2008).

A prudência é chave para compreender a deliberação na proposta de Diego Gracia e na pesquisa funciona como categoria analítica que permite desvendar as relações mediadoras dos achados por meio de um diálogo hermenêutico, problematizador que interroga as presunções dos discursos, não para julgá-las certas ou erradas, mas para traçar as tendências e, então, favorecer a tomada de consciência acerca da sensibilidade ética das ações e decisões (Zoboli, 2010). Assim, ultrapassa-se a mera descrição da prática moral e o julgamento moralizador, moralizante, dos achados. O propósito é compreender a lógica do equacionamento moral dos participantes da pesquisa frente aos conflitos, tomando como categoria analítica a prudência e como referencial metodológico parte do procedimento da deliberação. Os cursos de ação extraídos dos discursos são as categorias empíricas a serem relacionadas, analisadas, com referência à 'prudência'. Assim, o que se faz é deliberar sobre os dados empíricos. o propósito do artigo é apresentar um exemplo de pesquisa em bioética desenvolvida dentro desta proposta.

\section{Método}

Pesquisa qualitativa, compreensiva, caracterizando-se como uma integrated empirical ethics research, que buscou compreender, com sensibilidade interpretativa, uma experiência humana: a deliberação moral na clínica em APS. (Denzin \& Lincoln, 2006; Minayo, 2007). A "pesquisa empírica integrada em ética" ("integrated empirical ethics" ou "integrated empirical ethics research"; IEER) integra teoria ética e dados empíricos (Molewijk, Stiggelbout, Otten, Dupuis, \& Kievit, 2003; Molewijk, Stiggelbouti, Otten, Dupuis, \& Kievit, 2004). 
A integrated empirical ethics research (IEER) vem sendo engendrada como uma forma de pesquisa em bioética que transita entre os domínios normativo e descritivo, pois não se limita à descrição dos aspectos éticos de determinada prática social, mas almeja a compreensão, a interpretação destes, enfocando controvérsias morais, para que os resultados apontem questões normativas para o

A abordagem das questões

éticas integrando fatos, valores

e deveres, como proposto na

bioética deliberativa de Diego

Gracia, propicia o uso da

deliberação como referencial

teórico e metodológico em

"integrated empirical ethics

research". futuro. A integração do normativo e do empírico reconhece que ambos são mutuamente constitutivos da experiência moral pesquisada, ou seja, os fatos descritos entrelaçam-se com os valores epistêmicos, que estão sempre junto com os primeiros. (van der Scheer \& Widdershoven, 2004; Molewijk, Stiggelbouti, Otten, Dupuis, \& Kievit, 2004). Na IEER, a teoria ética não é só um referencial para a discussão dos achados, ao contrário, permeia toda a construção e desenvolvimento do estudo, possibilitando a interação entre os instrumentais de natureza científica usados para a descrição empírica da realidade e a teoria ética usada para compreender os valores implicados na situação e a gestão destes pelos envolvidos. 0 foco da IEER é a prática social e não os dados empíricos ou as teorias éticas isoladamente (Molewijk, Stiggelbouti, Otten, Dupuis, \& Kievit, 2004).

A abordagem das questões éticas integrando fatos, valores e deveres, como proposto na bioética deliberativa de Diego Gracia, propicia o uso da deliberação como referencial teórico e metodológico em IEER, como inovou o presente estudo.

Os 70 participantes eram enfermeiros (34) e médicos (36) de Unidades Básicas de Saúde do município de São Paulo (Brasil), organizadas por: Estratégia Saúde da Família (ESF); ações programáticas (UBS tradicional) e como Centros de Saúde Escola (CSE), vinculados à universidade. Os dados foram coletados em três projetos de pesquisa que tratavam da deliberação moral na clínica em APS, desenvolvidos entre 2000 e 2012, com financiamentos CNPq e Fapesp. Os Comitês de Ética em Pesquisa da Faculdade de Saúde Pública da Universidade de São Paulo (COEP 084/01) e da Secretaria de Saúde da Prefeitura Municipal de São Paulo. (427/2004 - CEPSMS) aprovaram eticamente os estudos. Para assegurar o anonimato dos participantes, registrou-se oralmente o consentimento ao início da gravação das entrevistas, após a leitura do Termo de Responsabilidade com informações da pesquisa e da pesquisadora, seguindo-se tempo para esclarecimentos necessários. As entrevistas eram feitas em lugar privativo, usualmente um consultório da UBS, segundo a escolha e disponibilidade do participante e de maneira a não atrapalhar os serviços. Antes de abordar os profissionais, solicitava-se autorização junto às coordenações regionais e direções das unidades, conforme os trâmites de cada serviço. Para a inclusão da unidade ou região a direção precisa concordar com as condições de confidencialidade das entrevistas.

Em entrevistas individuais, apresentava-se uma vinheta com um problema ético e perguntava-se ao entrevistado: ' $O$ que você recomendaria para os profissionais envolvidos nesse caso? Por quê?'. As vinhetas foram: 
a) PRESERVANDO A CONFIDENCIALIDADE (PC): O senhor $\mathrm{M}$ tem síflis. Ele não quer contar o que tem para sua esposa, mas quer protegê-la da doença. Enquanto está em tratamento, pede que se faça o exame em sua esposa sem que ela saiba.

b) ATENDENDO ADOLESCENTES (AA): B, 15 anos de idade, procura a unidade básica de saúde e conta que recentemente apaixonou-se por um rapaz de 16 anos. Seus pais acham que ela é muito jovem e a proíbem de namorar. A jovem diz que ainda não tem vida sexual ativa, mas pede uma prescrição de anticoncepcional oral. Também pede que nada seja contado aos seus pais.

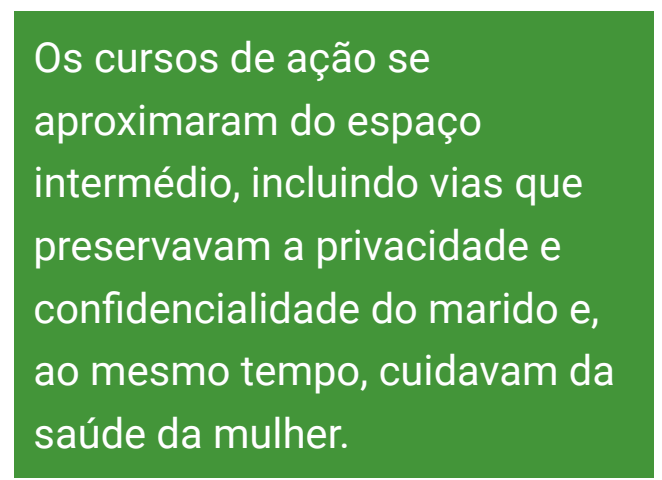

\section{Resultados}

A análise de conteúdo dos depoimentos gravados e transcritos visava isolar os cursos de ação recomendados, com a respectiva argumentação. A organização dos dados seguiu os procedimentos dos momentos de deliberação sobre os valores e deveres. Cada vinheta continha um problema moral fundamental e os cursos de ação para resolvê-lo, isolados na análise de conteúdo, foram organizados em um leque de possibilidades que incluía os dois extremos e os intermédios. 0 propósito era distinguir as tendências e discuti-las segundo a prudência, que se torna a categoria analítica quando se aplica a deliberação como referencial teórico-metodológico da pesquisa.

Os 70 participantes eram enfermeiros (18 da ESF, 09 das UBS tradicionais, 07 dos CSE) e médicos (17 ESF, 10 nas UBS tradicionais, 09 nos CSE). Dos enfermeiros, apenas um era do sexo masculino e dos médicos, 14. A idade dos enfermeiros variou de 22 a 53 anos, e a dos médicos, de 27 a 57 anos. Na ESF, o tempo de trabalho dos participantes em APS variou de 2 meses a 5 anos; na UBS tradicional foi de 2 a 26 anos, e nos CSE de 3 a 32 anos.

Na vinheta PC, os cursos de ação se aproximaram do espaço intermédio, incluindo vias que preservavam a privacidade e confidencialidade do marido e, ao mesmo tempo, cuidavam da saúde da mulher, com veracidade na relação clínica. 
Figura 1 - Problema ético e valores em conflito na vinheta 'Preservando a Confidencialidade'

\section{PRESERVANDO A CONFIDENCIALIDADE}

\section{Problema ético}

Como a equipe pode cuidar da saúde da mulher, sem faltar-Ihe com a verdade e honestidade e, ao mesmo tempo, respeitar o pedido do marido que não quer que ela saiba de sua doença?

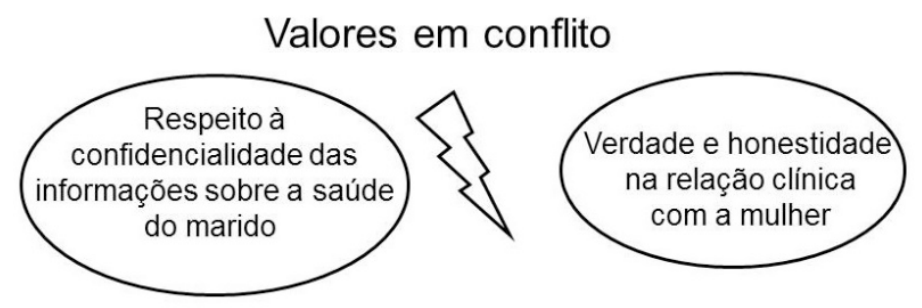

Considerando o conflito de valores, um dos cursos de ação extremos sacrificava a veracidade na relação clínica com a mulher e o outro o respeito à confidencialidade e privacidade do marido (Figura 2):

Figura 2 - Problema ético, valores em conflito e cursos de ação extremos na vinheta 'Preservando a Confidencialidade'

PRESERVANDO A CONFIDENCIALIDADE: Cursos Extremos de Ação

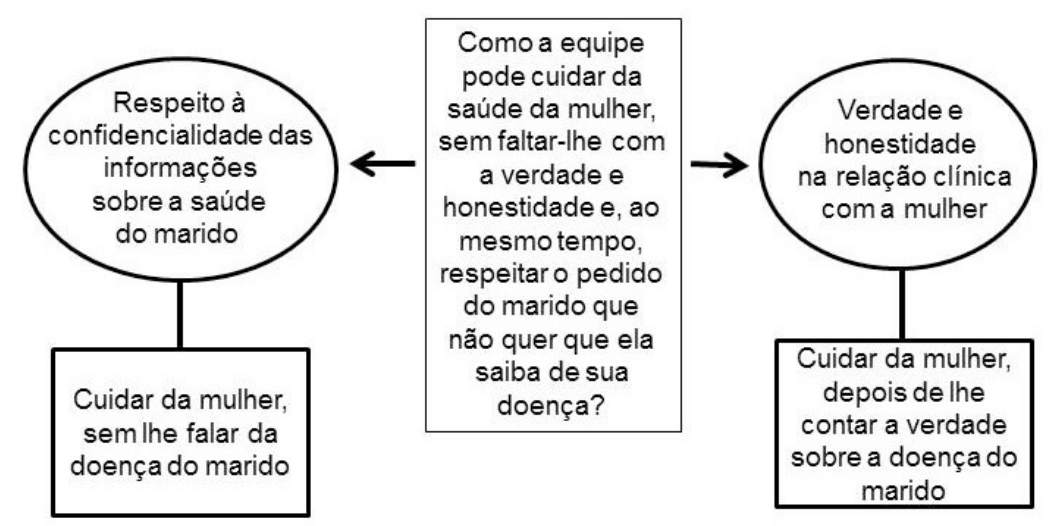

O problema ético principal funcionou como a pergunta de pesquisa da vinheta para qual se desejava reconhecer cursos de ação, sendo prudentes os que permitissem realizar ao máximo possível os valores em conflito, compaginando-os, isto é, as alternativas que 
permitissem cuidar da mulher, com ela sabendo da verdade, sem que isso significasse trair a confiança do marido quebrando unilateralmente o segredo pedido por este. Em ambas as possibilidades de cursos extremos incluía-se o tratamento da mulher.

Os dois cursos extremos e os 13 intermédios achados foram dispostos em um leque interpretativo das possibilidades para lidar com o conflito moral do problema ético principal da vinheta (quadro 1 ; figura 3 e 4 ).

\section{Quadro 1 - Cursos de ação recomendados pelos enfermeiros e médicos para a vinheta 'Preservando a Confidencialidade'}

CURSOS DE AÇÃO

A Solicitar exame diagnóstico de sífilis para a mulher somente depois de o marido contar-lhe a verdade

B Solicitar exame diagnóstico de sífilis para a mulher sem contar-lhe a verdade, mas estimulando que o marido o faça

c Solicitar exame diagnóstico de sífilis para a mulher sem contar-lhe a verdade; em caso de resultado positivo, estimular o marido a falar-lhe sobre a sua doença e se ele não quiser fazê-lo, a equipe deve contar

D Solicitar exame diagnóstico de sífilis para a mulher sem contar-lhe a verdade e sem estimular que o marido o faça

E Solicitar exame diagnóstico de sífilis para a mulher, sem contar-lhe a verdade se o relacionamento extraconjugal do marido for um episódio fortuito. Caso contrário, estimulá-lo a falar com sua mulher sobre sua doença

F Chamar a mulher para comparecer à unidade de saúde, estabelecer um bom vínculo com o casal e, depois disso, junto com o marido, revelar a verdade para sua esposa e solicitar-lhe o exame diagnóstico de sífilis

G Convocar a mulher para comparecer à unidade de saúde, contar-Ihe sobre a doença do marido e solicitar-Ihe o exame como controle de comunicante de doença sexualmente transmissível

Compartilhar a situação entre a equipe e o usuário para ajudá-lo a encontrar um modo de encaminhar a conversa

H com a esposa, orientando que, se ele quer protegê-la, deve usar preservativo nas relações sexuais e que a equipe não pode solicitar o exame sem que a mulher saiba do que está se passando

Chamar a mulher para uma consulta ginecológica, orientá-la ao uso do preservativo sob o pretexto de anticon-

I cepção, e, enquanto isso, convencer o marido a vir a uma consulta com ela para, junto com o profissional, contar-lhe a verdade e somente depois disso solicitar o exame diagnóstico de sífilis para a mulher

J Não contar nada para a esposa, não lhe solicitar o exame diagnóstico de sífilis e restringir-se a tratar o marido

K Pedir o exame diagnóstico de sífilis para a mulher, informando-lhe sobre isso, mas sem dizer o motivo da solicitação

Orientar o marido quanto à proteção de sua mulher por meio do uso de preservativos nas relações sexuais; tratá-

L -lo; convencê-lo de que está expondo a esposa a um risco para sua saúde; e, se a lei permitir, chamar a esposa para fazer o exame diagnóstico de sífilis

M Oferecer ao marido ajuda para contar a verdade à mulher e solicitar o exame diagnóstico de sífilis para ela somente depois do marido haver-lhe contado sobre sua doença 


\section{Preservando a confidencialidade: Cursos extremos e intermédios}

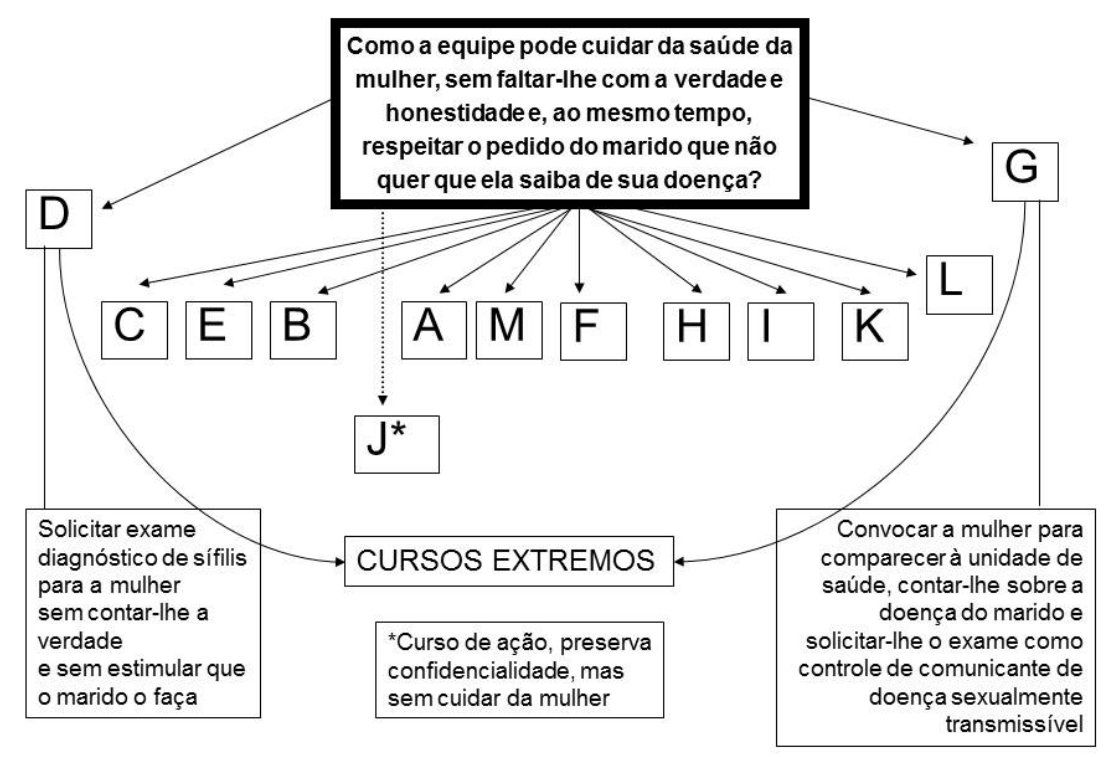

Figura 4 - Tendência no leque de cursos de ação para a vinheta 'Preservando a Confidencialidade'
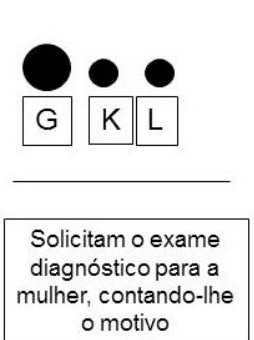
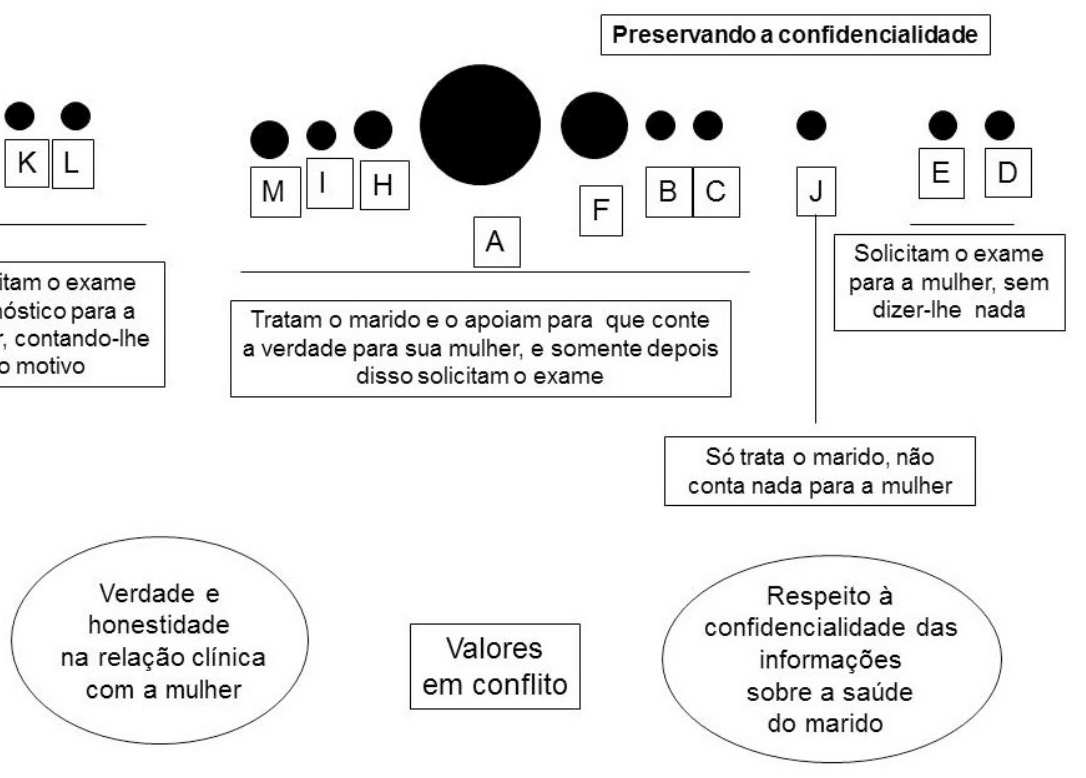

Na vinheta $A A$, a análise dos dados buscou respostas para o conflito de valores entre respeito à privacidade, confidencialidade da adolescente e à responsabilidade dos pais quanto à saúde dos filhos adolescentes (figura 5). 
Figura 5 - Problema ético e valores em conflito na vinheta 'Atendendo Adolescentes'

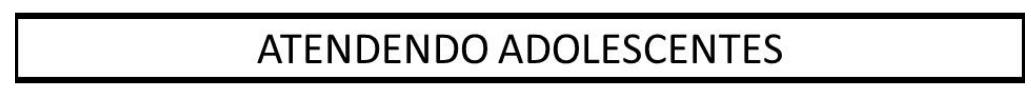

\begin{tabular}{|c|}
\hline Problema ético \\
Tendo em vista a responsabilidade dos pais quanto à saúde de seus filhos, como \\
respeitar a vontade da adolescente que pede à equipe que não lhes falem nada sobre a \\
prescrição de contraceptivo oral que está solicitando?
\end{tabular}

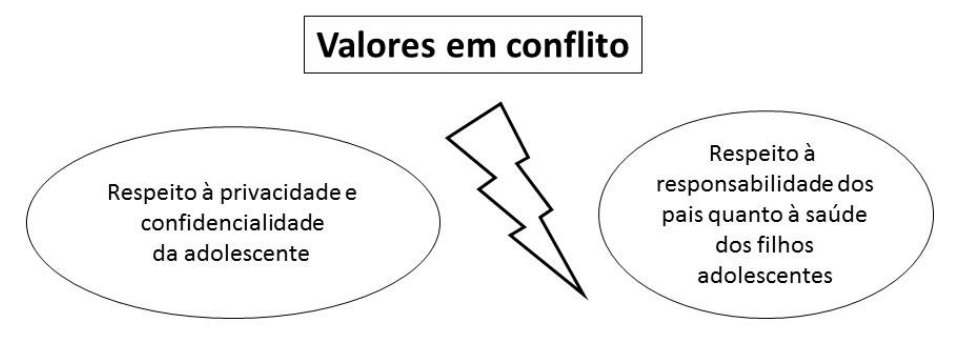

Num dos polos extremos, realizar-se-ia o valor respeito à privacidade e confidencialidade da adolescente e no oposto, respeito, ou consideração, à responsabilidade dos pais sobre a saúde de seus filhos adolescentes (figura 6).

Figura 6 - Problema ético, valores em conflito e cursos de ação extremos na vinheta 'Atendendo Adolescentes'

ATENDENDO ADOLESCENTES: Cursos de ação extremos

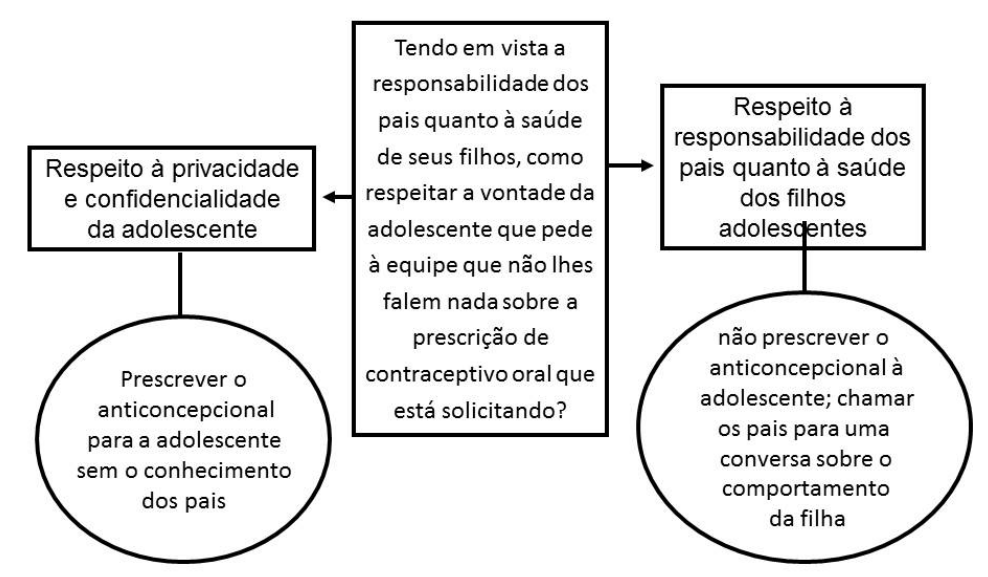


$\mathrm{Na}$ deliberação, tanto na pesquisa como na clínica, o problema ético fundamental nunca pode ser expresso como uma pendência de direitos morais e, muito menos, legais. A linguagem moral da deliberação são os valores e deveres e o problema ético é um conflito de valores.

Os 19 cursos de ação (quadro 2), considerando os extremos e o espaço intermédio, foram dispostos no leque hermenêutico, interpretativo (figuras 7 e 8 ).

\section{Quadro 2 - Cursos de ação recomendados pelos enfermeiros e médicos para a vinheta 'Atendendo}

\section{Adolescentes'}

\begin{tabular}{|c|c|}
\hline \multicolumn{2}{|r|}{ CURSOS DE AÇÃO } \\
\hline A & Prescrever o contraceptivo oral para a adolescente, sem contar para os pais e sem estimular que ela o faça \\
\hline B & Prescrever o contraceptivo oral sem contar nada para os pais, mas estimulando que a adolescente o faça \\
\hline C & Não prescrever o contraceptivo oral e estimular que a adolescente fale com os pais sobre a situação \\
\hline D & $\begin{array}{l}\text { Prescrever o contraceptivo oral para a adolescente e trabalhar com os pais dela no grupo de pais de adolescen- } \\
\text { tes }\end{array}$ \\
\hline E & $\begin{array}{l}\text { Atender a adolescente com outro profissional, fazer aconselhamento de enfermagem e encaminhar para o médi- } \\
\text { co }\end{array}$ \\
\hline $\mathbf{F}$ & $\begin{array}{l}\text { Não prescrever o contraceptivo oral para adolescente sem a ciência de seus pais e encaminhá-la para o grupo de } \\
\text { adolescentes e para a consulta médica }\end{array}$ \\
\hline G & Acolher a adolescente e ter um médico que possa legalmente prescrever para menores sem acompanhamento \\
\hline H & $\begin{array}{l}\text { Orientar a adolescente sobre vida sexual e reprodutiva, encaminhá-la ao médico para a prescrição do contracepti- } \\
\text { vo oral e chamar os pais para, junto com a filha, conversarem com a psicóloga }\end{array}$ \\
\hline $\mathbf{I}$ & Orientar a adolescente sobre vida sexual e reprodutiva, escolher o método mais indicado para ela e prescrevê-lo \\
\hline $\mathbf{J}$ & $\begin{array}{l}\text { Orientar a adolescente sobre vida sexual e reprodutiva, prescrever-lhe o contraceptivo oral; estimulá-la e apoiá-la } \\
\text { para que fale sobre a situação com sua mãe; oferecer apoio psicológico à mãe para que aceite a nova fase da } \\
\text { vida da filha }\end{array}$ \\
\hline K & Prescrever o contraceptivo oral para a adolescente e, em um segundo momento, trabalhar com os pais \\
\hline $\mathbf{L}$ & $\begin{array}{l}\text { Encaminhar a adolescente para um grupo de adolescentes, a fim de possa ser orientada sobre anticoncepção; } \\
\text { prescrever o contraceptivo e discutir com ela a importância da família estar ciente do que está se passando com } \\
\text { ela. }\end{array}$ \\
\hline $\mathbf{M}$ & $\begin{array}{l}\text { Não prescrever o contraceptivo oral para a adolescente; agendar-lhe retornos frequentes para conhecer melhor a } \\
\text { adolescente; estimulá-la a falar com seus pais, oferecendo-lhe apoio para isso, como chamar os pais e junto com } \\
\text { a adolescente conversar com eles }\end{array}$ \\
\hline $\mathbf{N}$ & $\begin{array}{l}\text { Não prescrever o contraceptivo oral para a adolescente; chamar a mãe para conversar e encaminhar a adoles- } \\
\text { cente para a psicóloga, para a 'saúde mental' ou o médico hebiatra }\end{array}$ \\
\hline 0 & Chamar o namorado; orientar o casal, para depois prescrever anticoncepção e preservativo \\
\hline $\mathbf{P}$ & $\begin{array}{l}\text { Explorar como é a relação da adolescente com os pais; orientá-la sobre saúde sexual e reprodutiva; prescrever- } \\
\text {-lhe método de contracepção e preservativo; estimulá-la para que fale com os pais sobre a situação }\end{array}$ \\
\hline $\mathbf{Q}$ & $\begin{array}{l}\text { Chamar o namorado; orientar o casal; prescrever anticoncepção e preservativo; estimular a adolescente para que } \\
\text { converse com os pais sobre a situação }\end{array}$ \\
\hline $\mathbf{R}$ & $\begin{array}{l}\text { Ganhar a confiança da adolescente; encaminhá-la para o grupo de planejamento familiar; prescrever anticoncep- } \\
\text { ção; visitar a família para conhecer a dinâmica familiar; trabalhar com os pais essa nova fase da filha }\end{array}$ \\
\hline$S$ & $\begin{array}{l}\text { Prescrever o contraceptivo oral; criar vínculo com a adolescente e com sua família; junto com a adolescente, } \\
\text { falar com seus pais sobre a situação }\end{array}$ \\
\hline
\end{tabular}




\section{ATENDENDO ADOLESCENTES: Cursos extremos e intermédios}

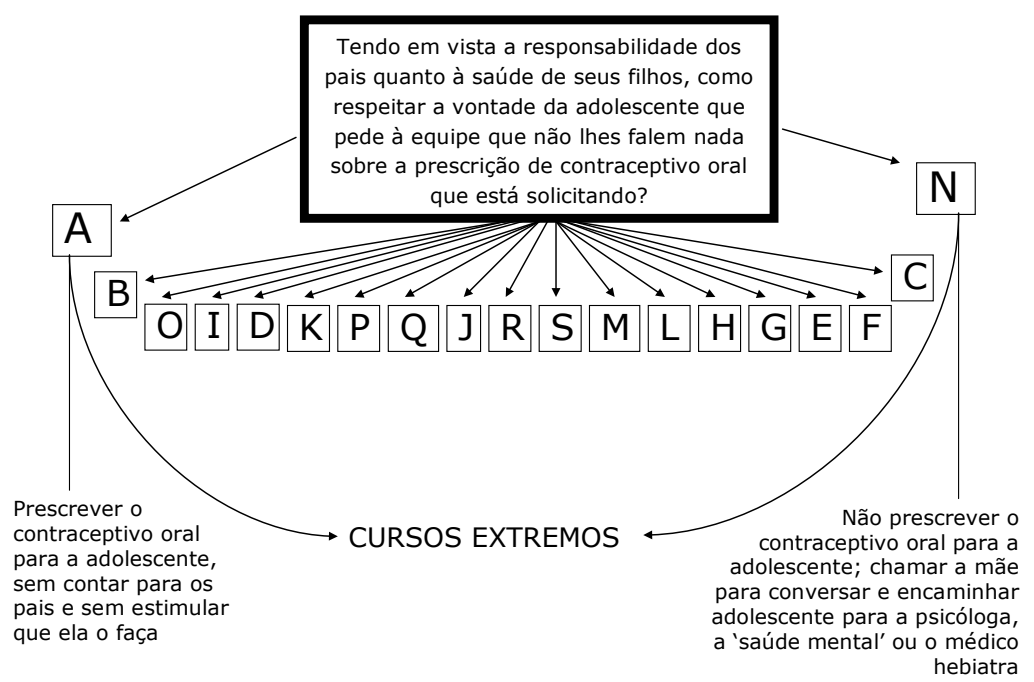

Figura 8 - Tendência no leque de cursos de ação para a vinheta 'Atendendo Adolescentes'

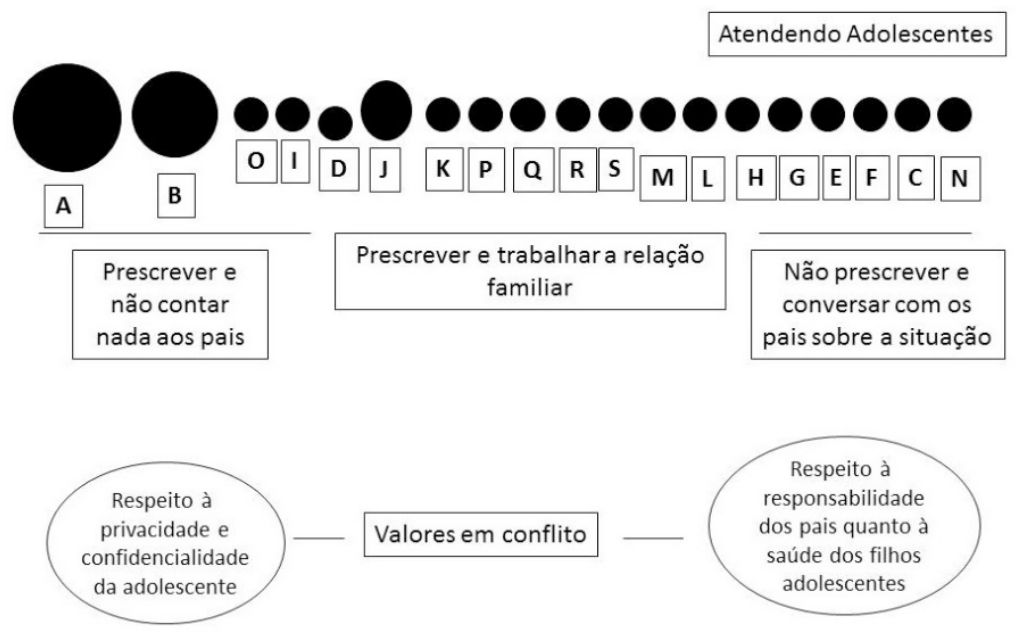

\section{Discussão}

A deliberação sobre os dados considerou a categoria analítica da 'prudência', que implicava o 'justo meio' entre o 'deveria' (intenções morais) e o 'deve' (ações morais). A prudência do curso de ação foi identificada por sua tendência aos cursos ótimos, ou intermédios, e pela argumentação incluindo a consideração do universal e do particular, condição necessária da categoria analítica tomada neste estudo. 
Após deliberar sobre os dados empíricos, pode-se compreender dos resultados que houve diferenças nas tendências dos cursos de ação para as duas vinhetas, tanto no espectro do leque de possibilidades como na direção em que tendiam. No PC, o espectro foi menor, com tendência aos cursos intermédios. No AA, o espectro de possibilidades foi mais amplo, entretanto, os cursos de ação penderam para um

As argumentações das

escolhas revelaram que a opção

pelo mal menor comprometeu

a busca pelo melhor, o curso

ótimo, que é o objetivo da ética. dos extremos. Considerando a categoria analítica, pode-se dizer que no PC os cursos de ação demonstraram mais prudência, recomendando soluções que salvavam, ou ao menos lesavam minimamente, os valores em conflito. Na vinheta AA, os cursos de ação foram para os extremos, realizando um dos valores em conflito e aniquilando o outro. Assim, no primeiro cenário, a deliberação foi mais prudente, apesar do leque mais restrito de possibilidades de cursos de ação. Na segunda vinheta, a opção pelo mal menor para solucionar o problema ético comprometeu a deliberação prudente, apesar do leque de possibilidades de cursos de ação de espectro mais amplo. As argumentações das escolhas revelaram que a opção pelo mal menor comprometeu a busca pelo melhor, o curso ótimo, que é o objetivo da ética; os cursos afastaram-se do espaço intermédio, onde costuma estar o ótimo, o prudencial. As argumentações justificativas das escolhas pelos cursos de ação indicaram a valoração da gravidez na adolescência; vista como mal maior, optava-se pelo menor, a prescrição de contraceptivos para a adolescente à revelia dos pais, ainda que algumas vezes se revelasse o medo de estar incorrendo em comportamento ilegal.

$\mathrm{Na}$ vinheta $\mathrm{PC}$ os discursos indicaram analogia com a recomendação do Conselho de Medicina (CREMESP, 2001) para parceiros sorodiscordantes de HIV/aids, que é conhecida pelos profissionais da APS, sendo que muitos entrevistados fizeram referência explícita a esta. Isto parece reforçar a importância da prática da deliberação nos fóruns coletivos, como os conselhos profissionais. Na vinheta AA, pesou a convivência dos entrevistados, em sua prática diária na APS, com a realidade da gravidez precoce na adolescência, comum nas regiões periféricas onde ficavam as unidades de saúde incluídas. Este cenário revela o desafio ético da melhoria das condições de vida no território com intervenções nos determinantes sociais dos agravos à saúde para ser possível a deliberação mais prudente.

Em situações como a da vinheta PC, as pessoas esperam que os profissionais ajam com prudência, mantendo a confidencialidade e dando apoio ao marido para revelar a verdade à mulher. Estudo exploratório, quanti-qualitativo com 'potenciais usuários do Sistema Único de Saúde' para identificar como esperam que os profissionais de saúde se comportem quando um dos parceiros de casal heterossexual tem sífilis, no qual se utilizou a vinheta PC, encontrou-se que os respondentes esperam dos profissionais a manutenção da confidencialidade, deixando a cargo do marido a revelação da verdade à esposa. 0 profissional foi visto como um mediador da situação, de quem esperavam orientação e apoio na revelação (Pisani \& Zoboli, 2009). Isto coincide com alguns dos cursos intermédios recomendados para a vinheta PC, assim, é possível afirmar que os usuários dos serviços esperam uma atitude prudente dos profissionais. A posição dos profissionais que valoram negativamente a gravidez na 
adolescência pode estar distante daquela dos usuários. Estudos com adolescentes grávidas, mães e pais adolescentes mostraram que, apesar da alteração que significa para os rumos de suas vidas, há muitos que valoram positivamente a experiência da gravidez, maternidade e paternidade. Estudo fenomenológico com adolescentes pais e mães recorrentes, em ambulatório público de São Paulo, mostrou que o aumento da responsabilidade consequente à parentalidade levou-os a reorganizar suas vidas, por meio de projetos, expectativas, desejos e sonhos, com a esperança de um futuro melhor (Carvalho, Merighi , \& Jesus , 2009). As valorações negativas da gravidez na vinheta AA podem ser devidas aos profissionais verem as situações unicamente pelos valores e visões de mundo pessoais, desconsiderando os valores e projetos dos usuários atendidos.

O entendimento da saúde como socialmente determinada requer profissionais prudentes, pois implica, necessariamente, a consideração dos valores, crenças e do projeto de vida de cada um, precisando o profissional na APS ter em conta os diferentes sistemas de valores, padrões culturais, religiosos e familiares dos usuários de quem cuida. Isso compromete o enriquecimento e a ampliação da clínica na APS e, consequentemente, a prudência dos cursos de ação na deliberação, pois os profissionais não reconhecem que a realidade é muito mais rica e complexa do que são capazes de conceber e apreender, mesmo nas situações corriqueiras e cotidianas. 0 entendimento da saúde como socialmente determinada requer profissionais prudentes, pois implica, necessariamente, a consideração dos valores, crenças e do projeto de vida de cada um, precisando o profissional na APS ter em conta os diferentes sistemas de valores, padrões culturais, religiosos e familiares dos usuários de quem cuida.

Devido à prudência, os cursos intermédios contribuem para a humanização das decisões nos conflitos morais. A deliberação representa a via humana, a justa medida, o curso de ação proposto por uma pessoa que se compreende como alguém que não é completamente sábia e tampouco inteiramente ignorante, que reconhece viver em um mundo que não é absolutamente racional ou absurdo (Aubenque, 2008). Em um paralelo com a clínica na APS, é possível afirmar que esta é reconhecida como uma prática que não é total ou exclusivamente racional e tampouco absurda, e o profissional de saúde vê-se como alguém que não é completamente sábio, tampouco totalmente ignorante. Assim, a deliberação, por levar os profissionais a perceberem conscientemente os limites, as potencialidades e as possibilidades deles próprios e da realidade, pode constituir-se via para a humanização da atenção à saúde.

Frenteaatitudes rígidase impositivas, porumlado,edespreocupadaseirresponsavelmente permissivas, por outro, há várias possibilidades de ações responsáveis, baseadas na deliberação participativa, na escuta atenta, no respeito da opinião de todos e na busca de atitudes razoáveis e prudentes. Entretanto, o despreparo dos profissionais para o manejo prudente, confiante dos problemas éticos na APS pode comprometer a relação de ajuda que integra a prática clínica (Gracia, Jarabe, Espíldora, \& Ríos, 2004). Ou seja, compromete uma relação clínica de emancipação, deliberativa e pautada pela prudência enquanto valor a ser realizado, em tempo propício, oportuno, na ocasião favorável (Pose, 2009). 


\section{Considerações finais}

O propósito deste artigo foi apresentar um exemplo da aplicação da deliberação, segundo a proposta de Diego Gracia, nas pesquisas em bioética. 0 estudo apresentado para exemplificar esta inovação para os desenhos de pesquisa empírica em ética explorou a interface da bioética com a APS, desenvolvendo-se como pesquisa empírica integrada em ética com vistas a compreender a deliberação dos profissionais frente a problemas éticos na prática clínica das unidades de saúde.

0 uso de vinhetas mostrou-se bom recurso para coleta de dados em pesquisas empíricas em bioética, pois frente a estas, os profissionais, para elaborar suas respostas, prontamente, recorriam ao que tinham vivido profissionalmente em situações idênticas ou similares. Esta forma de coleta de dados

Ao pesquisar em bioética, é

preciso refletir, questionar,

problematizar as questões

de fundo que subjazem aos

achados empíricos para avaliar

em que medida contribuem

para o respeito, a proteção

e a promoção da dignidade

humana. mobiliza as experiências vividas pelos participantes, permitindo ao pesquisador acessar, de certa maneira, o espaço dialético entre o 'idealizado' (representação) e o 'praticado' (ação), desde que a vinheta seja adequada à realidade dos participantes da pesquisa, o que implica a interação e proximidade do pesquisador com o objeto e cenário de estudo.

Os estudos qualitativos em bioética, pela especificidade do objeto, podem incorporar um procedimento de tomada de decisão como meio para estruturação do projeto, organização e interpretação dos achados; a função da pesquisa empírica em bioética não se resume a documentar vivências ou descrever atitudes, valores, princípios, escolhas, argumentações, acriticamente. A atitude crítica, não julgadora, do pesquisador sobre os achados pode desafiar os profissionais a confrontarem a realidade com as teorias éticas e a ampliar os horizontes normativos para lidar com os problemas éticos da prática clínica. Ao pesquisar em bioética, é preciso refletir, questionar, problematizar as questões de fundo que subjazem aos achados empíricos para avaliar em que medida contribuem para o respeito, a proteção e a promoção da dignidade humana. Se não for assim a pesquisa será um mero reflexo especular do costumeiro, perdendo-se de vista o característico da ética que é ser uma crítica dos costumes e, em tempos de medicina baseada em evidências, abre-se espaço para a falácia de uma ética baseada na evidência.

A aplicação da deliberação como referencial teórico-metodológico da pesquisa em bioética mostrou-se capaz de dar conta da dinâmica do objeto na vida real, pois possibilitou que a partir da situação apresentada os participantes incluíssem o que consideravam para lidar com o conflito de valores ensejado na vinheta. A adoção da prudência como categoria analítica permitiu a avaliação dos cursos de ação, sem incorrer em juízos do tipo 'certo' ou 'errado', 'correto' ou 'incorreto', com uma crítica compreensiva, por meio de um procedimento sistematizado. De fato, o que se fez foi aplicar o procedimento deliberativo sobre os achados, ou seja, deliberar sobre os dados empíricos encontrados, propiciando-se a necessária integração das abordagens filosófica e empírica na pesquisa em bioética, com resultados que apontam horizontes normativos para o futuro da prática estudada. 


\section{Referências}

Aubenque, P. (2008). A prudência em Aristóteles. ( $2^{\mathrm{a} e d}$.). São Paulo: Paulus, Discurso Editorial.

Carvalho , G., Merighi , M., \& Jesus , M. (2009). Recorrência da parentalidade na adolescência na perspectiva dos sujeitos envolvidos. Texto \& Contexto de Enfermagem , 18 (1) 17-24.

CREMESP. (2001). AIDS e ética médica. São Paulo: Conselho Regional de Medicina do Estado de São Paulo.

Dalla Nora, C., Zoboli, E. L., \& Vieira, M. (jan-mar de 2015). Problemas éticos vivenciados por enfermeiros na atenção primária à saúde: revisão integrativa da literatura. Revista Gaúcha de Enfermagem, 36, 112-21.

Denzin, N. K., \& Lincoln, Y. S. (2006). A disciplina e a prática da pesquisa qualitativa. In: N. K. Denzin, Y. S. Lincoln, N. K. Denzin, \& Y. S. Lincoln (Eds.), O planejamento da pesquisa qualitativa: teorias e abordagens. Porto Alegre: Artmed, 15-41.

Gracia , D., Jarabe , Y., Espíldora , N., \& Ríos , J. (2004). Toma de decisiones con el paciente menor de edad. In: D. Gracia, \& J. Júdez ,Ética en la práctica clínica. Madrid: Editorial Triacastela, Fundación Ciencias de la Salud, 126-160.

Gracia, D. (1992). Metodos de analisis de problemas éticos en la clínica humana. Anales de la Real Academia Nacional de Medicina. Madrid: Universidad Complutense de Madrid , 371-86.

Gracia, D. (enero-julio de 2009). Deliberación Moral. El papel de las metodologías en ética clínica. Material didáctico del curso. Madrid, España: Universidad Complutense de Madrid.

Junges, J. R. (2014). Bioética Sanitarista: desafios éticos da saúde Coletiva. São Paulo: Loyola.

La Taille, Y. (2006). Moral e ética: dimensões intelectuais e afetivas. Porto Alegre: Artmed.

Leder, D. (1994). Toward a hermeneutical bioethics. In: E. R. DuBose, R. Hamel , \& L. J. O'Connell , A Matter of Principles?: Ferment in U.S. Bioethics. Valey Forge: Trinity Press International , 240-59.

Minayo, M. C. (2007). O desafio do conhecimento: pesquisa qualitativa em saúde. 10a ed. São Paulo: Hucitec.

Molewijk, B., Stiggelbout, A. M., Otten, W., Dupuis, H. M., \& Kievit, J. (March de 2003). Implicit Normativity in Evidence-Based Medicine: a plea for integrated empirical ethics research. Health Care Anal., 11 (1) 6992.

Molewijk, B., Stiggelbouti, A., Otten, W., Dupuis, H., \& Kievit, J. (April de 2004). Empirical data and moral theory. A plea for integrated empirical ethics. Med Health Care Philos., 7, 55-69.

Pellegrin, P. (2007). “Prudência” [verbete]. In: M. Canto-Sperber, \& M. Canto-Sperber (Ed.), Dicionário de Ética e Filosofia Moral (Vol. 2, 406-11). São Leopoldo: UNISINOS.

Pisani, J., \& Zoboli, E. C. (jul/set de 2009). Doenças Sexualmente Transmissíveis: preservar a confidencialidade do marido ou proteger a saúde da mulher? Cogitare Enferm UFPR, 14, 476-83.

Pose, C. (2009). Lo bueno y lo mejor: introducción a la bioética médica. Madrid: Editorial Triacastela.

van der Scheer, L., \& Widdershoven, G. (April de 2004). A response to Levitt and Molewijk. Med Health Care Philos, 1, 89-91.

Zoboli, E. C. (jan-mar de 2012). Bioética clínica na diversidade: a contribuição da proposta deliberativa de Diego Gracia. Bioethikós, 6 (1) 49-57. 
Zoboli, E. C. (set-dez de 2013). Tomada de decisão em bioética clínica: casuística e deliberação moral. Revista Bioética, 21 (3) 389-396.

Zoboli, E. L. (2010). Deliberação: leque de possibilidades para compreender os conflitos de valores na prática clínica da atenção básica. Universidade de São Paulo, Escola de Enfermagem . São Paulo: EEUSP.

Zoboli, E. L., \& Fortes, P. A. (nov-dez de 2004 ). Bioética e atenção básica: um perfil dos problemas éticos vividos por enfermeiros e médicos do Programa Saúde da Família, São Paulo, Brasil. Caderno de Saude Pública, 20 (6) 1690-99. 